\title{
Development and validation of an inventory to measure stressful events: Findings from a population-based survey
}

\author{
Fateh Tavangar ${ }^{1,2}$, Hassan Rafiey*1,2®D Ahmad Ali Noorbala ${ }^{3}$, Farhad Nosrati Nejad ${ }^{4}$, Gholamreza Ghaedamini Harouni ${ }^{1,2}$, \\ Hesam Ghiasvand ${ }^{4}$, Fardin Alipour ${ }^{5}$, Sina Ahmadi ${ }^{1,2}$
}

Received: 16 Jan 2019

Published: 16 May 2020

\section{Abstract}

Background: Development of tools for measuring stress has been considered by mental health researchers for many years. The purpose of this study was to develop and validate a "Stressful Events Inventory"(SEI) using exploratory and confirmatory factor analyses.

Methods: Using a representative sample $(n=6000)$ from all people who reside in Tehran, the validity of the inventory was confirmed by exploratory and confirmatory factor analyses, and its reliability was also confirmed by Cronbach's alpha.

Results: Eleven major sets of stressful events were identified as follow: political problems $(\alpha=0.731)$, neighborhood's problems $(\alpha=0.739)$, livelihood problems $(\alpha=0.609)$, fear of the future $(\alpha=0.663)$, educational events $(\alpha=0.635)$, educational changes $(\alpha=0.704)$, individual changes $(\alpha=0.463)$, occupational difficulties $(\alpha=0.64)$, housing problems $(\alpha=0.69)$, problems related to occupational relations $(\alpha=0.46)$, and family problems $(\alpha=0.69)$. The value of correlation between the factors was equal to 0.82 and the value of variance determined by these factors was $0.49\left(\mathrm{r}^{\wedge} 2=0.49\right)$. In the confirmatory factor analysis, these factors also had an appropriate fitness (RMSEA=0.02).

Conclusion: The developed instrument has suitable psychometric properties, which make it appropriate for future research on psychosocial stress.

Keywords: Stress, Stressful event inventory, Exploratory factor analysis, Confirmatory factor analysis

Conflicts of Interest: None declared

Funding: University of Social Welfare and Rehabilitation Science

\section{*This work has been published under CC BY-NC-SA 1.0 license.}

Copyright $\odot$ Iran University of Medical Sciences

Cite this article as: Tavangar F, Rafiey H, Noorbala AA, Nosrati Nejad F, Ghaedamini Harouni Gh, Ghiasvand H, Alipour F, Ahmadi S. Development and validation of an inventory to measure stressful events: Findings from a population-based survey. Med J Islam Repub Iran. 2020 (16 May);34:48. https://doi.org/10.47176/mjiri.34.48

\section{Introduction}

Stress is one of the most common phenomena in modern urban life. The complexity of urban interactions, everyday conflicts, traffic and noise pollution, densely populated areas of the cities, inaccessibility to facilities, poor quality of family life, low socioeconomic status, inappropriate housing, inability to manage stress and low resilience, and most importantly, socioeconomic inequality play important roles in the formation and frequency of social stressors (1-3).

Corresponding author: Dr Hassan Rafiey, ha.rafiey@uswr.ac.ir

1. Department of Social Welfare Management, University of Social Welfare and Rehabilitation Science, Tehran, Iran

2. Social Welfare Management Research Center, University of Social Welfare and Rehabilitation Science, Tehran, Iran

3. Psychosomatic Medicine Research Center, Tehran University of Medical Science, Tehran, Iran

4. Social Determinants of Health Research Center, University of Social Welfare and Rehabilitation Science, Tehran, Iran

5. Social Work Department, University of Social Welfare and Rehabilitation Science, Tehran, Iran
Stress is a multidimensional phenomenon that originates from different sources, and is the outcome of biological, psychological, and sociological factors $(4,5)$. Conceptualization and measurement of social stressors must shift from focusing on specific events to observing and evaluating a set of social factors that influence the formation of stress in different places and times (6). Ecological models indicate that stress and its experience are affected by many factors

$\uparrow$ What is "already known" in this topic:

Since decades, researchers are seeking to build a comprehensive instrument that can accurately assess and measure stressful events. Due to the evolution of stressors, the need for evolution of precise and comprehensive tools that assess these stressors is felt more than ever.

$\rightarrow$ What this article adds:

For the first time, a comprehensive instrument for measuring stressful events is developed according to contingencies of living in Tehran. 
at individual and environmental levels. Understanding these factors and their impact is important in controlling severe stress and long-term survival (7).

Attention to multiple sources of stressful events in people's lives, especially in the modern era, is needed for a comprehensive, up-to-date conceptualization of stress. The existence of these two characteristics is related to the inherent nature of stress. Since the stress and mental conflict are generated by different social determinants at different micro, meso and macro levels $(3,8-10)$, any tool that intends to measure and evaluate stress and mental conflicts should consider all these determinants and factors at different levels from personal and private to social factors as well as factors at subjective and objective levels.

The construction and validation of stress assessment tools and stressful events have attracted many researchers from the fields of social wellbeing and health, as well as psychology and sociology. Admi et al. (11) constructed and validated a multicultural tool among 2616 Israeli nurses in 23 hospitals. In this research, exploratory and confirmatory factor analysis was used to ensure the validity of the tools and internal reliability of the items. The main causes of stressful events among nurses are patient and family complaints, lack of resources, responsibility burden, and professional conflict. In this research, inter-factor correlation is $83.3 \%$.

The metropolis of Tehran, as the political and economic capital of Iran, has undergone the greatest amount of urban transformation over the past five decades. Unbalanced urban growth in Tehran, accompanied by widespread immigration from nearly all cities and villages of the country, has been accompanied by growing stressful events $(12,13)$. Noorbala et al. found that $82.7 \%$ of Tehran's residents in 2016 experienced a severe stressful event. Regarding the classification of stressful events in this study, the highest frequency of stressful events is concerns related to personal and familial future $(53.7 \%)$, the second is financial and economic concerns $(47.1 \%)$, and the third concern is the high cost of living (41.7\%) (14).

For decades, researchers are seeking to build a comprehensive tool that can accurately assess and measure stressful events. Due to the evolution of stressors, the need for evolution of precise and comprehensive tools that assess these stressors is felt more than ever. Developing a tool able to measure the stressful events requires the study of sources of stress as well as the approval of related experts. Furthermore, such tool should consider the modern factors of stress, such as job migration, isolation and loneliness, declining social trust, addiction to industrial drugs, neighborhood problems, and economic crisis. In addition, the necessity for making a tool to measure stressful events in our country comes from the fact that existing tools that are mainly developed in Western societies (15-19) are tailored to meet the needs of those societies. However, the tool in our study was developed by investigating other tools and solving their deficiencies, and also by paying attention to the structure and socio-economic status of Tehran metropolis. Considering the fact that the stressful events inventory is designed in Tehran, which is the political and economic capital of Iran, it considers the urban characteristics and social harms at the neighborhood and macro levels. Therefore, this tool is native to the city of Tehran, and has been designed for the first time.

\section{Methods}

\section{Stressful Events Inventory}

The item pool had seven sections, including individual events, family events (for married people), financial and economic events, occupational and work events (for employed people), educational events (for students), neighborhood and community events, and future events. In general, this comprehensive inventory encompassed 159 events that may cause stress.

The item pool has been developed in various stages. In the first stage, a comprehensive review of available scientific resources was carried out to enlist stressful events. Some of the most important resources included: Holmes and Rahe's stressful situation questionnaires, the study of Burden of Stress (BOS) in the United States, and a list of stressful events of people attending the counseling centers of Iran's Social Welfare Organization(14, 20). At the next stage, this primary list of psychosocial stressors was given to 27 experts in the field of mental and social health, and then after confirming the quality of the content based on simplicity, relevance, clarity, and necessity, their comments were applied. Subsequently, four focused group discussions (FGD) were held in four areas of Tehran, and the opinions of citizens regarding the checklist were obtained, and the necessary amendments were made to the checklist. In the final step, the checklist was implemented as a pilot study on the sample of 50 people to check its understandability and feasibility. Also, to measure the demographic variables such as age, sex, education, marital status, region of residence, employment status, income, housing, and family asset, a checklist that had been prepared for this purpose was used. Detailed description is published elsewhere (14).

\section{Sample size and sampling method}

Assuming the highest variance in the statistical population $\left(\sigma^{2}=0.25\right)$, the sample size for each level of the analysis with a $95 \%$ confidence interval, and an absolute error of 0.05 was calculated.

The highest distribution has been used for these reasons:

a) The population of previous studies in Iran estimating the prevalence of stress was limited to nurses and administrative staff, which could not be used in our study on all residents of Tehran.

b) Regarding the fluctuations in the prevalence of stress in Iranian society, using previous estimations may increase the estimation error.

c) Considering the sampling method (PPS) and the necessity of exploratory and confirmatory factor analyses, proper sample size was necessary.

The sample size was calculated to be 665 individuals for each level of analysis. Finally, by taking into account the three socio-economic status (high, middle and low) in Tehran, as well as three age groups of young (18-39 years), middle-aged (40 to 59 years) and elderly (60 years and 
older), the size of the sample was determined to be 6000 individuals. The sample size was determined for each of the 22 districts of Tehran proportional to their population size (PPS). A detailed description of the sampling method is published elsewhere (14).

Because of socio-economic diversity within each district, all neighborhoods of each district were divided into three categories of high, medium, and low socio-economic status in terms of their housing prices. Then, a neighborhood from each socio-economic level was randomly selected. In other words, sampling was carried out in 66 neighborhoods of Tehran (14). Therefore, participants were selected randomly from three socio-economic status, two genders, and three age groups in 22 districts of Tehran.

\section{Exploratory and Confirmatory Factor analysis}

Exploratory factor analysis (EFA) was used to identify the factors that existed among the variables. The KaiserMeyer-Olkin (KMO) index was used to ensure the adequacy of the sample for factor analysis. The KMO index was 0.822 in this study, indicating that the items had required correlation and reliability for factor analysis. An SPSS software version 22 was used to perform the exploratory factor analysis (EFA), and for the confirmatory factor analysis (CFA), AMOS software version 22 was used.

In EFA by SPSS software, there are several ways to rotate the factors that require logical choice based on correlation. Thus in the first stage, we used the Direct-Oblimin rotation, which was more appropriate for highly correlated factors. In addition, this rotation yield a matrix of factors correlation, which can be used to decide on orthogonal versus oblique rotations.

According to the results obtained from EFA, factors associated with the variables of stressful events did not have a significant correlation with each other, and in other words, the oblique rotation was not appropriate, so an orthogonal rotation should be chosen. Logically, stressful events were related to particular categories, and these categories did not have any significant correlation with each other (a series of events in the checklist). For orthogonal factor rotation, we could use Varimax, Quartimax, and
Equamax rotations. Since we were faced with a wide range of stressful variables for measuring stressful events, from which many factors are formed (in the first phase, about 54 factors out of 159 variables were formed), it was logical to adopt a method for the rotation of variables that could load the least factors with the most variable. In the Varimax, the number of questions that are loaded on the factors is minimized; therefore, this method was not suitable for our factor analysis. In the Quartimax rotation, the number of factors is minimized, and this rotation was more suitable for our purpose. The Equamax rotation is also a compromise between the two rotations. Thus, we used Quartimax rotation for our factor analysis (21).

We divided our data into two random groups of 3000 people and then, EFA and CFA were performed on the two separate, independent groups.

In order to perform CFA, the AMOS program was used, which confirmed the final model after examining the internal correlation of items with factors. Considering the number of indicators that validate the model in CFA (about 30 indicators), we used some of the most important fitness indicators, which included GFI (Goodness of Fit Index), TFI (Tucker-Lewis Index), NFI (Non-standard Fit Index), CFI (Comparative Fit Index) of greater than 0.9, RMSEA (Root Mean Square Error) of less than 0.05, and CMIN / DF (normalized Chi-square to degree of freedom).

\section{Results}

In EFA, a total of 11 factors were extracted, and the value of explained variance was equal to $\left(R^{2}=0.49\right)$. Also, Cronbach's Alpha of 0.822 showed its reliability. In Table 1 , the names of the extracted factors and the variables that are correlated with them are presented; meanwhile, the Cronbach's alpha value for each factor is also listed below the Factors.

In order to have acceptable goodness of fit in the CFA, the factor loads had to be greater than $0.4(20)$. The measurement model could only be approved and used, if the fitness indicators were appropriate and suitable. As shown in the diagram below, most factor loads were more than 0.4 or close to this figure, except for the variable number 18 of the

Table 1. Factors and items related to stressful events

\begin{tabular}{ll}
\hline Factors & Variable (Stressful Events) \\
\hline Political Problems & 1. Insecurity to express political aspirations and opposition \\
(Cronbach's Alpha=0.739) & 2. Watch, read or hear the words and actions of politicians \\
& 3. Frequent change in domestic and foreign policies and community rules \\
& 4. Corruption in the police, court, government departments and agencies, municipality and so on \\
& 5. Safety problems (uncertainty about food health, road and vehicle safety) \\
& 6. Social discrimination \\
& 7. Uncertainty about the real people's perspective \\
8. Watch, read or hear controversial political news or speeches & 9. Internet Problems (Filtering, Slowness, etc.) \\
& \\
1. Living in a place where a person is faced with drug use scenes \\
2. Living in a neighborhood where a person faces poverty scenes (begging, elderly work and adult \\
garbage) \\
3. Living in the neighborhood where the person faces with other people's unemployment \\
4. Low economic, social and cultural level of the neighborhood \\
5. Living in the neighborhood where the person faces the scenes of others' violence \\
6. Living in the neighborhood where the person faces with scenes of prostitution \\
7. High crime and low sense of security in the neighborhood \\
8. Living in the neighborhood where the person faces the scene of child labor
\end{tabular}




\begin{tabular}{|c|c|}
\hline \multicolumn{2}{|l|}{ Table 1. Ctd } \\
\hline Factors & Variable (Stressful Events) \\
\hline \multirow{6}{*}{$\begin{array}{l}\text { Livelihood and wage problems } \\
\text { (Cronbach's Alpha=0.609) }\end{array}$} & 1. Salary problems \\
\hline & 2. Uninsured by the employer \\
\hline & 3. Expensive daily necessities \\
\hline & 4. Education expenditures of family members \\
\hline & 5. Exposure to unexpected costs \\
\hline & 6. Market instability \\
\hline Fear of the future & 1. Concerned about individual and family future \\
\hline \multirow[t]{4}{*}{ (Cronbach's Alpha $=0.663$ ) } & 2. Concerns about the financial and economic future \\
\hline & 3. Concerns about the future of education \\
\hline & 4. Concerns about the future of the job \\
\hline & 5. Concerns about the future of the neighborhood and society \\
\hline Educational events & 1. Doing homework, presenting content in class, exam and dissertation \\
\hline \multirow[t]{4}{*}{$($ Cronbach's Alpha $=0.635)$} & 2. The problem of interpersonal relationships in education \\
\hline & 3. Dormitory problems \\
\hline & 4. Educational failure \\
\hline & 5. Financial difficulties during the education years \\
\hline Educational changes & 1. Change the field of study \\
\hline \multirow[t]{2}{*}{ (Cronbach's Alpha $=0.704)$} & 2. Changes in education regulations \\
\hline & 3. Change in the educational environment \\
\hline Individual changes & 1. Change in sleep habits \\
\hline \multirow[t]{5}{*}{$($ Cronbach's Alpha $=0.463)$} & 2. Reach old age \\
\hline & 3. Change in your hobbies \\
\hline & 4. Change in performing religious rituals \\
\hline & 5. Changes in social activities \\
\hline & 6. Change in beliefs, attitudes and thoughts \\
\hline Job difficulty & 1. Extreme and overwhelming job responsibilities \\
\hline \multirow[t]{4}{*}{$($ Cronbach's Alpha $=0.642)$} & 2. Time pressure for job tasks \\
\hline & 3. Problem with manager \\
\hline & 4. Problems with working physical conditions \\
\hline & 5. The problem of transportation between work and home \\
\hline Problems of Job Relationships & 1. Emotional abuse at work (disregard, humiliation, disturbance, swearing, etc.) \\
\hline \multirow[t]{2}{*}{$($ Cronbach's Alpha $=0.464)$} & 2. Problems in interpersonal relationships, disputes, and issues \\
\hline & 3. No control over work \\
\hline Family relationships & 1. Wife's Treachery \\
\hline \multirow[t]{5}{*}{ (Cronbach's Alpha=0.689) } & 2. Controversy with wife and leave home \\
\hline & 3. Interventions of husband and wife families \\
\hline & 4. Psychological Abuse by your’ wife \\
\hline & 5. Conflict with family members \\
\hline & 6. Being obliged to live in a different family cultural \\
\hline
\end{tabular}

checklist (reaching the old age), which was loaded on factor 7 (stressful events due to individual changes), and eliminating it did not change the fitness indicators. Meanwhile, their statistical significance was confirmed. In Figure 1, the correlation coefficient of 11 factors together and the factor load are shown.

More than 30 model fit indicators have been introduced, most of which are reported in the Amos software output, but some of them are of higher importance and have been reported in most studies. These indicators have some thresholds for a fit model. If the GFI (Goodness of Fit Index), TFI (Tucker-Lewis Index), (NFI) Non-standard Fit Index, CFI (Adaptive Fit Index) are greater than 0.9, and RMSEA (Root Mean Square Error) is less than 0.05, and CMIN / DF (normalized Chi-square to degree of freedom) is between 1 and 5, then the fitness of model is appropriate (20). In Table 2, the value of the index obtained in the AMOS software is shown, and according to the acceptable value for each index, the model is fitted.

\section{Discussion}

Due to a lack of tools for measuring stressful comprehensive events in developing cities such as Tehran, the aim of the present study was to construct and validate an instrument for measurement a range of stressful events from macro to micro levels. After EFA and CFA, 11 factors were identified as the main psychosocial stressors. These factors are political problems, social problems and neighborhood underdevelopment, livelihood problem, fear of the future, educational change, educational events, individual change, job difficulty, problems of job relationship and family relationship problems. Many of these factors had a common characteristic, which indicated that respondents were most concerned and anxious about the transitional periods and changes in politics and other social and cultural spheres (individual changes, changes in academic rules, changes in domestic and foreign politics, and changes in the family system). Worrying about the future was also a reflection of these concerns. All of these stressors reflected the ongoing transition of the urban community in Iran. In addition, the factors related to livelihood and social problems and underdevelopment of the neighborhood were also among the most significant factors in the tool of stress events.

The method used to develop a tool for the measurement of stressful events in this research is similar to the research of Admi et al. (11) In their research, they used the intercultural tool to measure the level of stress in nurses of Israel's hospitals, which its reliability (internal consistency) confirmed by Cronbach' alpha and credibility had been confirmed by exploratory and confirmatory factor analysis. 


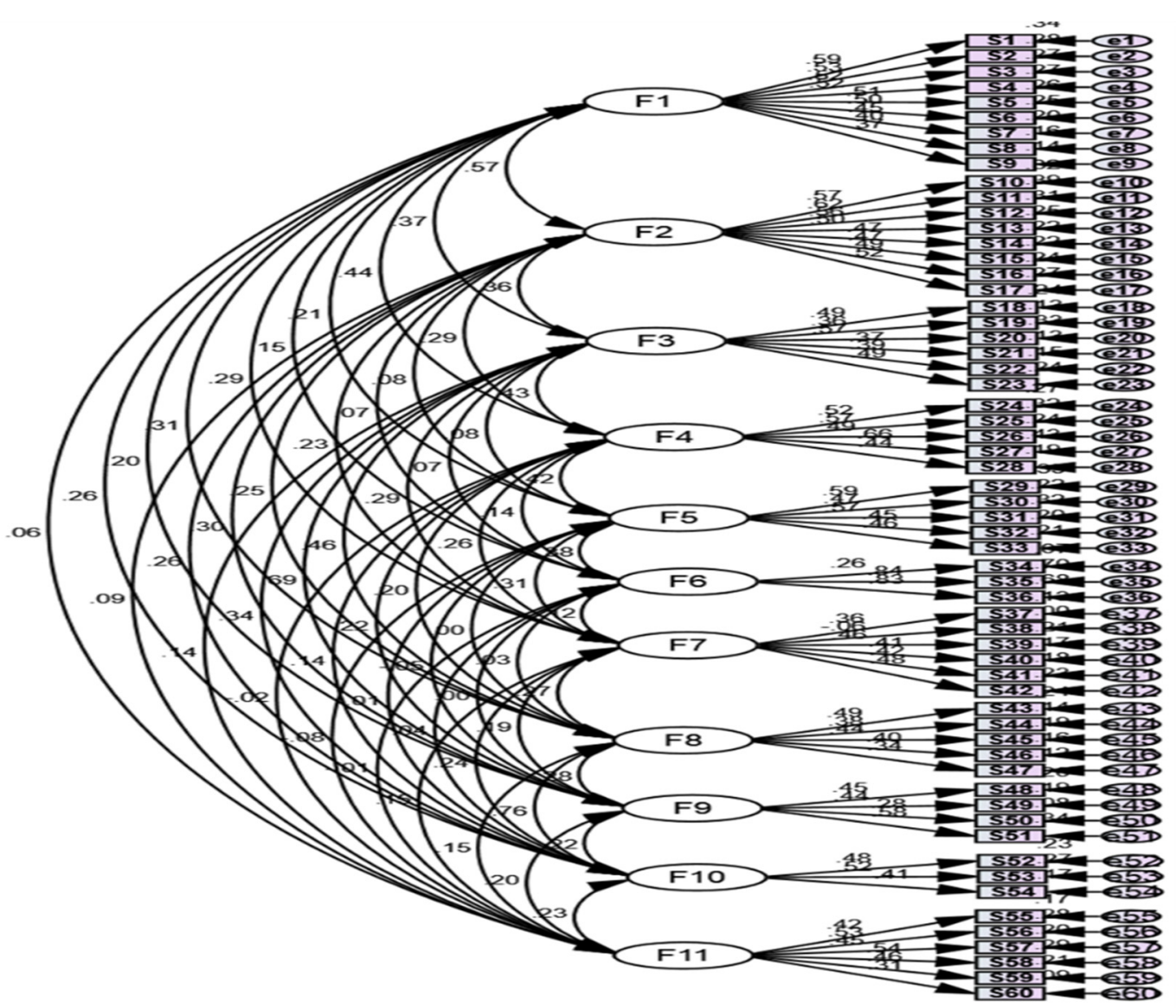

Fig. 1. Correlations of factors and factor load of variables

Table 2. Fitness Index stressful events inventory

\begin{tabular}{lcccccc}
\hline & CMIN/DF & GFI & CFI & NFI & TIL & RMSEA \\
\hline Calculated & 4.48 & 0.959 & 0.882 & 0.894 & 0.873 & 0.024 \\
Acceptable count & From 1 to 5 & 0.9 & 0.9 & 0.9 & 0.9 & 0.05 \\
\hline
\end{tabular}

The researchers used the exploratory and confirmatory factor analysis for tool development that is in line with our preferred method. The Charge Nurse Stress Questionnaire (CNSQ), like our research checklist (SEI), includes a series of events that lead to stress in the nurses. The main difference between CNSQ and SEI is that SEI is a common tool used among all occupational classes and social stratifications, but CNSQ applies just to charge nurses.

The results of this research have similarities and differences with the results of Agrowal et al. study (19). In their study, in order to test and develop tools for measuring stressful events at young age among the adult Indians, they used a 41-item scale, which was formulated by 156 young people and validated by 102 others. In our research, there were all age groups, and the tool was not limited to use in a specific age group. On this scale, which was indigenous to the Indian society and compatible with the characteristics of the youth in that society, the transitional periods and the comparative problems that existed for Indian youth at that time had been viewed as stressors. According to the transformation of stressful events, it would seem attractive to create tools for measuring stressful events in any period of time.
Valerie et al. (18) and McKay (22) examined the reliability and validity of the Adolescent Stress Questionnaire (ASQ). Their results showed that the ASQ was a reliable, valid instrument for adolescent stress. Our research method is exploratory and confirmatory analysis, while these researchers have used confirmatory factor analysis. Despite sharing in stressful events, they differ in some factors, such as the underdevelopment of the neighborhood and political problems and livelihood problems. These factors are more prominent in our research. School-Leisure conflict, Teacher interaction, Homelife, adult responsibility, life satisfaction are some of the extracted factors in Valerie's research.

\section{Conclusion}

The lack of a comprehensive and well-designed instrument that evaluates the stressful events in cities, especially cities in developing countries at macro and micro levels, is felt. This study aimed to develop and validate a stress events inventory using quantitative methods among the factors obtained. In this study, the first factor was the major policies and general governance of the country, which in- 
dicated the concern of the general public with political decisions at the macro level. The second factor was the underdevelopment of the community and the existence of social problems, which are serious issues. The third factor was the concern about livelihood, the cost of everyday living, and low wages and salaries, which have been a source of anxiety and stress for the past few decades. Although, this study had several limitations such as including low $R^{2}$ value and lack of test-retest investigation in the respondents, this instrument as a comprehensive instrument has suitable reliability and validity, and is suggested to be used in psychosocial research.

\section{Acknowledgments}

The authors wish to thank the Psychosocial Health and Addiction Office of the Ministry of Health and Medical Education of Iran and the University of Social Welfare and Rehabilitation Science.

\section{Conflict of Interests}

The authors declare that they have no competing interests.

\section{References}

1. Mubi Brighenti A, Pavoni A. City of unpleasant feelings. Stress, comfort and animosity in urban life. Soc Cult Geogr. 2017:1-20.

2. Roe JJ, Aspinall PA, Ward Thompson C. Coping with Stress in Deprived Urban Neighborhoods: What Is the Role of Green Space According to Life Stage? Front Psychol. 2017;8:1760.

3. Knöll M, Neuheuser K, Cleff T, Rudolph-Cleff A. A tool to predict perceived urban stress in open public spaces. Environ Plan B Urban Anal City Sci. 2018;45(4):797-813.

4. Tausig M, Michello J, Sree S. Sociology of Mental Illness. 3, editor. Tehran: SAMT; 2014. $420 \mathrm{p}$.

5. Folkman S, Lazarus RS, Gruen RJ, DeLongis A. Appraisal, coping, health status, and psychological symptoms. J Pers Soc Psychol. 1986;50(3):571.

6. Costa ALS, Polak C. Construction and validation of an instrument for the assessment of stress among nursing students. Rev Esc Enferm USP. 2009;43(SPE):1017-26.

7. Wang H, Yang XY, Yang T, Cottrell RR, Yu L, Feng X, et al. Socioeconomic inequalities and mental stress in individual and regional level: a twenty one cities study in China. Int J Equity Health. 2015;14(1):25.

8. Gadalla TM. Determinants, correlates and mediators of psychological distress: A longitudinal study. Soc Sci Med. 2009;68(12):2199-205.

9. Lederbogen F, Haddad L, Meyer-Lindenberg A. Urban social stressrisk factor for mental disorders. The case of schizophrenia. Environ Pollut. 2013;183:2-6.

10. Kocalevent RD, Levenstein S, Fliege H, Schmid G, Hinz A, Brähler E, et al. Contribution to the construct validity of the Perceived Stress Questionnaire from a population-based survey. J Psychosom Res. 2007;63(1):71-81.

11. Admi H, Eilon Y, Renker P, Unhasuta K. Stress measurement among charge nurses: developing a cross-cultural tool. J Adv Nurs. 2016;72(4):926-35

12. Kaviani A, Mansourian H, Farhoudi R. Urban growth pattern in Tehran City: Sustainability or unsustainability. Gateways. 2017;1(1):59-70.

13. Fard HR. Urbanization and informal settlement challenges: Case study Tehran metropolitan city. Open House Int. 2018;43(2):77-82.

14. Noorbala AA, Rafiey H, Alipour F, Moghanibashi-Mansourieh A. Psychosocial stresses and concerns of people living in Tehran: a survey on 6000 adult participants. Iran J Psychiatry. 2018;13(2):94.

15. Nielsen MG, Ørnbøl E, Vestergaard M, Bech P, Larsen FB, Lasgaard $\mathrm{M}$, et al. The construct validity of the Perceived Stress Scale. J Psychosom Res. 2016;84:22-30.

16. Darviri C, Legaki PE, Chatzioannidou P, Gnardellis C, Kraniotou C, Tigani X, et al. Adolescent Stress Questionnaire: Reliability and validity of the Greek version and its description in a sample of high school (lyceum) students. J Adolesc. 2014;37(8):1373-7.

17. Simonelli-Muñoz AJ, Balanza S, Rivera-Caravaca JM, Vera-Catalán T, Lorente AM, Gallego-Gómez JI. Reliability and validity of the student stress inventory-stress manifestations questionnaire and its association with personal and academic factors in university students. Nurse Educ Today. 2018;64:156-60.

18. Sotardi VA, Watson PWSJ. A sample validation of the Adolescent Stress Questionnaire (ASQ) in New Zealand. Stress Health. 2018;135:3-14

19. Aggarwal S, Prabhu CH, Anand LCA, Kotwal LCA. Stressful life events among adolescents: The development of a new measure. Indian J Psychiatry. 2007;49(2):96.

20. Schmitt TA. Current methodological considerations in exploratory and confirmatory factor analysis. J Psychoeduc Assess. 2011;29(4):304-21.

21. Corner S. Choosing the right type of rotation in PCA and EFA. JALT Test. 2009;13(3):20-5.

22. McKay MT, Percy A, Byrne DG. Support for the multidimensional adolescent stress questionnaire in a sample of adolescents in the United Kingdom. Stress Health. 2016;32(1):12-9. 